\title{
Status of salivary lipid peroxidation in oral cancer and precancer
}

\author{
Shishir Ram Shetty, \\ Subhas Babu, \\ Suchetha Kumari ${ }^{1}$, \\ Pushparaja Shetty ${ }^{2}$, \\ Shruthi Hegde, \\ Renita Castelino
}

Departments of Oral Medicine and Radiology and ${ }^{2}$ Oral Pathology, $A B$ Shetty Memorial Institute of Dental Science, ${ }^{1}$ Department of Biochemistry, KS Hegde Medical Academy, Nitte University, Mangalore, Karnataka, India

\author{
Address for correspondence: \\ Dr. Shishir Ram Shetty, \\ Reader, Department of Oral \\ Medicine and Radiology, AB \\ Shetty Memorial Institute of Dental \\ Sciences, Deralakatte, Mangalore, \\ Karnataka, India. \\ E-mail: drshishirshettyomr \\ @yahoo.com
}

\section{A B S T R A C T}

Introduction: Lipid oxidation gives rise to number of secondary by-products. Malondialdehyde (MDA) is the principal and most widely studied product of polyunsaturated fatty acid peroxidation. This aldehyde is a highly toxic molecule and should be considered as more than just a marker of lipid peroxidation in oral carcinogenesis. Materials and Methods: Salivary malondiadldehyde was evaluated in 65 healthy controls (HC), 115 subjects with oral, potentially malignant disorders (PMD) and 50 subjects with oral squamous cell carcinoma (OSCC) using the Thiobarbituric-Trichloroacetitic acid (TBA-TCA) method. Results: A consistent elevation in the levels of salivary MDA was observed in HC with tobacco related habits, subjects with PMD and subjects with OSCC. The elevation in the salivary MDA was significant $(P=0.001)$ in the groups PMD and OSCC and group OSCC when compared to HC. Conclusion: The significant and encouraging findings of this study thus validate and reinforce that salivary malodialdehyde analysis can be used as an efficient, noninvasive tool for the early diagnosis of PMD and OSCC for planning comprehensive treatment protocol.

Key words: Malodialdehyde, oral leukoplakia, potentially malignant disorders, saliva

\section{INTRODUCTION}

Reactive oxygen species induced damage of the cells produces lipid peroxidation end products such as malondialdehyde (MDA), a well-established biomarker of oxidative stress. ${ }^{[1]}$ An increase in serum MDA concentrations have been widely reported in various cancers even in early stages. ${ }^{[2]}$ An increased amount of lipid peroxidation end products have been demonstrated in tumor tissue itself, clearly pointing to the source of increased MDA levels in cancer patients. ${ }^{[2,3]}$

Malondialdehyde is a highly toxic aldehyde molecule, which is considered to be an ideal marker of lipid peroxidation. ${ }^{[3]}$ With this background, we carried out a study to evaluate the salivary MDA levels in subjects with oral squamous

\begin{tabular}{|l|l|}
\hline \multicolumn{2}{|c|}{ Access this article online } \\
\hline Quick Response Code: & Website: \\
\hline & www.jmpo.org \\
\cline { 2 - 2 } & \\
\hline
\end{tabular}

cell carcinoma (OSCC) and potentially malignant disorders (PMD).

\section{MATERIALS AND METHODS}

A cross-sectional study was conducted on 230 subjects, were in the age group of 20-60 years reporting to the Department of Oral Medicine. Among the 230 subjects, 65 healthy controls (HC) formed (Group HC). The PMD group consisted of 115 patients with the following conditions: 65 patients of oral submucous fibrosis (OSMF) and 50 patients of oral leukoplakia (OL). The OSCC group consisted of 50 OSCC patients. Group HC was divided into two subgroups - HC1 which consisted of $\mathrm{HC}$ without quid chewing and/or smoking habits and HC2 with quid chewing and/or smoking habits. Patients with systemic illness, long-term drug intake, previous history of malignancy or history of antioxidant medication were excluded. Ethical approval was obtained from the Institutional Ethical Committee and informed consent was obtained from all the study subjects. Unstimulated saliva was collected from the study subjects between 9:00 a.m. and 12:00 p.m. to avoid diurnal 
variation. The subjects were requested not to eat, drink, perform oral hygiene activities or chew 60 min prior to the saliva collection procedure. The subjects were then seated on the dental chair and asked to spit in a graduated container every 1 min till $5 \mathrm{ml}$ of saliva was obtained. During saliva collection, subjects were instructed not to speak or swallow. The salivary samples were stored at a temperature of $-20^{\circ} \mathrm{C}$. Estimation of MDA was done by the TBA-TCA method, wherein the salivary samples were heated with TBA-TCA reagent in a water bath for $20 \mathrm{~min}$. The reagent consisted of $20 \%$ TCA, $0.5 \%$ TBR and $2.5 \mathrm{~N}$ HCL. After cooling, the solution was centrifuged at $2000 \mathrm{rpm}$ for $10 \mathrm{~min}$ and the precipitate was removed. The absorbance of the supernatant was determined at $532 \mathrm{~nm}$ against blank that contained all the reagents minus the biological sample. The MDA equivalents of the sample were calculated using an extinction coefficient of $1.56 \times 10^{5} \mathrm{M}^{-1} \mathrm{~cm}^{-1}$. Statistical analysis of the data was performed by using the SPSS version 17 software. Scheffe's test was used in conjunction with an ANOVA for comparison between multiple unequal groups.

\section{RESULTS}

The mean salivary MDA levels of group HC1 was $0.1812 \pm 0.0341 \mathrm{nmol} / \mathrm{ml}$ and group HC2 $0.2176 \pm 0.0341 \mathrm{nmol} / \mathrm{ml}$. The mean salivary levels of group OL was $0.4175 \pm 0.0321 \mathrm{nmol} / \mathrm{ml}$ and group OSMF was $0.4344 \pm 0.0421 \mathrm{nmol} / \mathrm{ml}$. The mean salivary MDA levels of group OSCC was $0.9306 \pm 0.0319 \mathrm{nmol} / \mathrm{ml}$ [Figure 1].

The mean salivary MDA levels of group HC1 was significantly lower compared to group PMD $(P=0.001)$. The mean salivary MDA levels of group OSCC was significantly higher $(P=0.01)$ when compared to group HC1. Further, the mean salivary MDA levels of group OSCC was significantly higher when compared to group

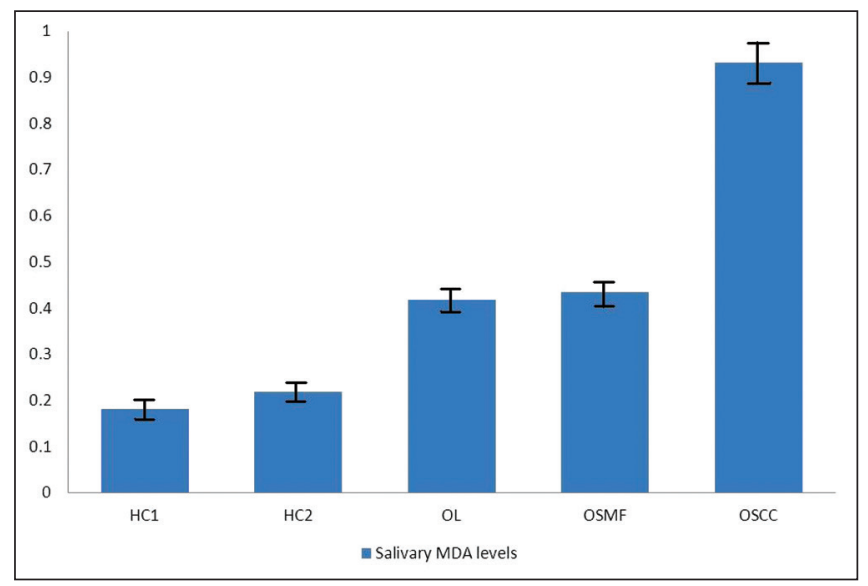

Figure 1: Mean salivary malondialdehyde levels in the study groups
$\operatorname{PMD}(P=0.001)$ [Tables 1 and 2]. There was no statistically significant difference in the mean salivary MDA levels between group OL and OSMF. When the mean salivary MDA levels of group HC1 were compared to group HC2, the mean salivary levels of MDA was found to be significantly higher $(P=0.05)$ in group HC2 [Table 3].

\section{DISCUSSION}

Of the many biological targets of oxidative stress, lipids are the most commonly involved class of bio-molecules. Lipid oxidation gives rise to a number of secondary by-products. MDA is the principal and most widely studied product of polyunsaturated fatty acid peroxidation. Its interaction with DNA and proteins has often been referred to as potentially mutagenic and atherogenic. ${ }^{[3,4]}$

In this study, a significantly higher salivary MDA level was observed in the OSCC group, when compared to the HC1 group. This is in accordance with recent studies where they found significantly elevated levels of serum lipid peroxidation products including lipid hydroperoxide and MDA in HNSCC patients when compared to controls. ${ }^{[4,5]}$ The possible reason for the increased MDA levels in OSCC is due to the widely reported fact that cancer cells have a

\section{Table 1: Comparison of the mean serum and salivary MDA levels in the study groups}

\begin{tabular}{lccccc}
\hline Parameter & $n$ & Mean & SD & $\begin{array}{c}F \\
\text { (ANOVA) }\end{array}$ & $P$ \\
Salivary MDA HC1 & 35 & 0.1812 & 0.0341 & 63.004 & $<0.001$ HS \\
PMD & 115 & 0.4259 & 0.0371 & & \\
OSCC & 50 & 0.9306 & 0.0319 & &
\end{tabular}

ANOVA test; HS - Highly significant; SD - Standard deviation; MDA - Malondialdehyde; PMD - Potentially malignant disorders; OSCC - Oral squamous cell carcinoma

Table 2: Pair-wise comparison of serum and salivary MDA levels in the study groups

$\begin{array}{lcccc}\begin{array}{l}\text { Dependent } \\ \text { variable }\end{array} & \text { (I) group } & \text { (J) group } & \begin{array}{c}\text { Mean difference } \\ (\mathrm{I}-J)\end{array} & \boldsymbol{P} \\ \text { Salivary MDA } & \mathrm{HC}_{1} & \text { PMD } & 0.2447 & 0.001 \\ & & \text { OSCC } & 0.7494 & 0.001 \\ & \text { PMD } & \text { OSCC } & 0.5047 & 0.001\end{array}$

Post-hoc test; MDA - Malondialdehyde; PMD - Potentially malignant disorders; OSCC - Oral squamous cell carcinoma

Table 3: Comparison of the serum and salivary MDA levels in between the study groups $\mathrm{HC} 1$ and $\mathrm{HC} 2$

\begin{tabular}{lccccc} 
Parameter & Group & $\boldsymbol{n}$ & Mean & SD & $P$ \\
Salivary MDA & $\mathrm{HC}_{1}$ & 35 & 0.1812 & 0.0341 & 0.05 \\
& $\mathrm{HC}_{2}$ & 30 & 0.2176 & 0.0341 & \\
\hline
\end{tabular}

Student's t-test; MDA - Malondialdehyde; SD - Standard deviation 
propensity to produce large amount of free radicals that leads to increase in lipid peroxidation.

Studies on oral cancer and various human cancers have reported and highlighted similar findings as noticed in this study, validating the fact that there exists a relationship between free radical activity, lipid peroxidation and malignancy. ${ }^{[0-8]}$

In this study, a significantly higher salivary MDA level was observed in the PMD and OSCC groups, when compared to group HC1. This is in accordance with a recent salivary study, where, a significantly elevated level of MDA in OL, OSMF and OSCC was observed when compared to controls. ${ }^{[9]}$ Another recent study stated that the salivary MDA levels were higher in OL patients when compared to $\mathrm{HC}$ but not statistically significant. ${ }^{[10]}$

Owing to the relatively few number of salivary MDA studies in PMD and OSCC patients, this study suggests that salivary MDA could serve as a potential diagnostic marker in PMD and OSCC.

\section{REFERENCES}

1. Dalle-Donne I, Rossi R, Colombo R, Giustarini D, Milzani A. Biomarkers of oxidative damage in human disease. Clin Chem 2006;52:601-23.

2. Bitla AR, Reddy P, Sambasivaih K, Suchitra MM, Reddy S, Rao PS. Evaluation of plasma malondialdehyde as a biomarker in patients with carcinoma of stomach. Biomed Res 2011;22:63-8.

3. Del Rio D, Stewart AJ, Pellegrini N. A review of recent studies on malondialdehyde as toxic molecule and biological marker of oxidative stress. Nutr Metab Cardiovasc Dis 2005; 15:316-28.

4. Beevi SS, Rasheed AM, Geetha A. Evaluation of oxidative stress and nitric oxide levels in patients with oral cavity cancer. Jpn J Clin Oncol 2004;34:379-85.

5. Rasheed MS, Beevi SS, Geetha A Enhanced lipid peroxidation and nitric oxide products with deranged antioxidant status in patients with head and neck squamous cell carcinoma. Oral Oncol 2007;43:333-8.

6. Bor NM, Unver Y, Kilinc K, Dereagzi H. Tissue malondialdehyde levels in zinc deficient rats. J Islam Acad Sci 1994;7:74-7.

7. Ekanayaka PR, Tilakaratne WM. Oral submucous fibrosis: Review on mechanisms of pathogenesis and malignant transformation. J Carcinog Mutagen 2013;5:1-11.

8. Portakal O, Ozkaya O, Erden Inal M, Bozan B, Kosan M, Sayek I. Coenzyme $\mathrm{Q} 10$ concentrations and antioxidant status in tissues of breast cancer patients. Clin Biochem 2000;33:279-84.

9. Rai B, Kharb S, Jain R, Anand SC. Salivary lipid peroxidation product malonaldehyde in various dental diseases. World J Med Sci 2006;1:100-1.

10. Guven Y, Unur M, Bektas K, Uslu E, Belce A, Demirez E. Salivary malondialdehyde levels in patients with oral leukoplakia. Turk J Med Sci 2005;35:329-32.

How to cite this article: Shetty SR, Babu S, Kumari S, Shetty P, Hegde Sh, Castelino R. Status of salivary lipid peroxidation in oral cancer and precancer. Indian J Med Paediatr Oncol 2014;35:156-8. Source of Support: Nil. Conflict of Interest: None declared.

\section{New features on the journal's website}

Optimized content for mobile and hand-held devices

HTML pages have been optimized of mobile and other hand-held devices (such as iPad, Kindle, iPod) for faster browsing speed.

Click on [Mobile Full text] from Table of Contents page.

This is simple HTML version for faster download on mobiles (if viewed on desktop, it will be automatically redirected to full HTML version)

\section{E-Pub for hand-held devices}

EPUB is an open e-book standard recommended by The International Digital Publishing Forum which is designed for reflowable content i.e. the text display can be optimized for a particular display device.

Click on [EPub] from Table of Contents page.

There are various e-Pub readers such as for Windows: Digital Editions, OS X: Calibre/Bookworm, iPhone/iPod Touch/iPad: Stanza, and Linux: Calibre/Bookworm.

\section{E-Book for desktop}

One can also see the entire issue as printed here in a 'flip book' version on desktops.

Links are available from Current Issue as well as Archives pages.

Click on View as eBook 